\title{
SFCFOS Uniform and Chebyshev Amplitude Distribution Linear Array Antenna for K-Band Applications
}

\author{
Venkata Kishore Kothapudi · Vijay Kumar
}

\begin{abstract}
In this study, a compact series-fed center-fed open-stub (SFCFOS) linear array antenna for K-band applications is presented. The antenna is composed of a single-line 10-element linear array. A symmetrical Chebyshev amplitude distribution (CAD) is used to obtain a low sidelobe characteristic against a uniform amplitude distribution (UAD). The amplitude is controlled by varying the width of the microstrip patch elements, and open-ended stubs are arranged next to the last antenna element to use the energy of the radiating signal more effectively. We insert a series-fed stub between two patches and obtain a low mutual coupling for a 4.28-mm center-to-center spacing $(0.7 \lambda$ at $21 \mathrm{GHz})$. A prototype of the antenna is fabricated and tested. The overall size of the uniform linear array is $7.04 \times 1.05 \times$ $0.0563 \lambda_{g}{ }^{3}$ and that of the Chebyshev linear array is $9.92 \times 1.48 \times 0.0793 \lambda_{g}{ }^{3}$. The UAD array yields a $\left|S_{11}\right|<-10 \mathrm{~dB}$ bandwidth of 1.33\% (20.912-21.192 GHz) and 1.45\% (20.89-21.196 GHz) for the CAD. The uniform array design gives a $-23 \mathrm{~dB}$ return loss, and the Chebyshev array achieves a $-30.68 \mathrm{~dB}$ return loss at the center frequency with gains of $15.3 \mathrm{dBi}$ and $17 \mathrm{dBi}$, respectively. The simulated and measured results are in good agreement.
\end{abstract}

Key Words: Chebyshev Amplitude Distribution (CAD), Linear Array, Microstrip, Series-Fed Center-Fed Open-Stub (SFCFOS), Uniform Amplitude Distribution (UAD).

\section{INTRODUCTION}

Series-fed patch array antennas have been known for many years [1] and have also been examined in the context of traveling wave and resonator antennas [2]. For the standard resonator array antenna, each half-wavelength patch is separated by a uniform $\lambda / 2$ - transmission line. This important characteristic will lead to a uniform aperture distribution with a broadside radiation pattern if all patches have the same width. In a uniform series antenna circuit model, all radiation resistances of the same value are generally in parallel.

Owing to the half-wavelength patch and line length, these types of antennas provide only a single-frequency operation.
Microstrip patch array antennas are widely applied in radar systems [3-6] and wireless communications systems [7-10], which have a high gain, a light weight, a low cost, and a low profile and can accurately control radiation patterns. Resonant and traveling-wave feeds are commonly used in a series-fed structure. The bandwidth of a traveling-wave feed is wider than that of a resonant feed $[8,9]$. However, the main beam angle changes in accordance with the change in operating frequency, which is caused by the change in the relative phase difference between two adjacent elements along the series-fed lines.

Several designs have recently been made to suppress the sidelobe level (SLL) in the printed antenna arrays [10-18]. A new aperture is proposed in [10] microstrip antenna array. The an-

Manuscript received May 6, 2018 ; Revised August 2, 2018 ; Accepted November 22, 2018. (ID No. 20180506-036J)

Department of Communication Engineering, School of Electronics Engineering (SENSE), Vellore Institute of Technology, Vellore, Tamil Nadu, India.

"Corresponding Author: Venkata Kishore Kothapudi (e-mail: v.k.kothapudi@ieee.org)

This is an Open-Access article distributed under the terms of the Creative Commons Attribution Non-Commercial License (http://creativecommons.org/licenses/by-nc/4.0) which permits unrestricted non-commercial use, distribution, and reproduction in any medium, provided the original work is properly cited.

(c) Copyright The Korean Institute of Electromagnetic Engineering and Science. All Rights Reserved. 
tenna consists of $100 \times 50$ planar array microstrip elements with an inter-element spacing of $0.51 \lambda$, and a $-20.9 \mathrm{~dB}$ SLL is obtained. In [11], the authors presents a SLL suppression method for an X-band antenna array by designing a novel feeding network with a Chebyshev distribution. The array operates at $9.3 \mathrm{GHz}$ and can give a $-19.4 \mathrm{~dB}$ SLL, and the gain is only $12.3 \mathrm{dBi}$. A linear series-fed six-element antenna array is presented in [12]. A 6.5\% wideband is obtained, but the SLL and the acquired gain remain poor at $-20 \mathrm{~dB}$ and $14.2 \mathrm{dBi}$, respectively. Lower SLLs are dealt with and obtained in $[13,14]$. The optimized distribution coefficients through the differential evolution algorithm have been used to achieve a wideband and a lower SLL in the slot antenna with a series-fed network in [13]. The antenna has 10 elements arranged in a series feeding system. The SLL and the half-power beamwidth (HPBW) are $-25.3 \mathrm{~dB}$ and $8.4^{\circ}$, respectively. However, the gain is only 14.5 dBi. In addition, Nikkhah et al. [14] propose a low SLL and wideband series-fed antenna for the dielectric resonator (DRA). The proposed antenna can achieve a very low $-30 \mathrm{~dB}$ SLL and a high $19 \mathrm{dBi}$ gain. A $22 \times 1$ linear array results in a large size and fabrication complexity. Similarly, two other DRA arrays are introduced in $[15,16]$. The array in [15] works at $60 \mathrm{GHz}$ and that in [16] operates at 7.4 GHz. The SLLs are $-27.7 \mathrm{~dB}$ and $-23 \mathrm{~dB}$, respectively. In $[17,18]$, two linear series-fed Yagi-like array samples are presented. The arrays have 22 similar Yagi line elements, which can provide a gain of $15.3 \mathrm{dBi}$ and an SLL of about $-27 \mathrm{~dB}$. A literature comparison is presented in [13-16, 19-21] for both uniform and Chebyshev amplitude distributions (CAD).

In this study, a series-fed center-fed open-stub (SFCFOS) uniform amplitude distribution (UAD) and Chebyshev amplitude distribution (CAD) linear arrays are designed and applied to achieve a SLL of $-25 \mathrm{~dB}$ and gain enhancement. Two seriesfed linear array antennas with UAD and CAD at the same operating frequency are fabricated, and scattering parameters and radiation characteristics are measured. The amplitude can be controlled by varying the patch width that has been implemented. A $\lambda_{g} / 2$ open-ended stub is introduced at both the ends of the array, so that the energy remaining after the last element is reflected from the open stub and radiates into the space.

\section{ANTENNA ARRAY STRUCTURE AND DESIGN}

This section introduces a design process of two types of antenna arrays with different configurations. In addition, uniform linear array (ULA) and Chebyshev linear array (CLA) antenna arrays using the corresponding linear polarized-antenna elements are also presented. Here, we define the $x z$-plane as the vertical plane (E-plane or $\phi=0^{\circ}$ ) and $y z$-plane as the horizontal plane $\left(\mathrm{H}\right.$-plane or $\left.\phi=90^{\circ}\right)$. The whole design is analyzed with the aid of the full-wave electromagnetic solver CST Microwave Studio (CST Computer Simulation Technology GmbH, Darmstadt, Germany).

Fig. 1 shows the top and bottom views of the geometry of the UAD and CAD linear array antennas, respectively. The antenna is composed of a microstrip patch array, a series feed, and coaxial probe center-feed structures (substrate and Brass plate). Both arrays are designed with 31 mil with 1 oz., that is, a 0.035 mm-thick copper RT/Duroid-5880 (Rogers Corp., Chandler, AZ, USA) copper cladding substrate with relative permittivity $\varepsilon_{r}$

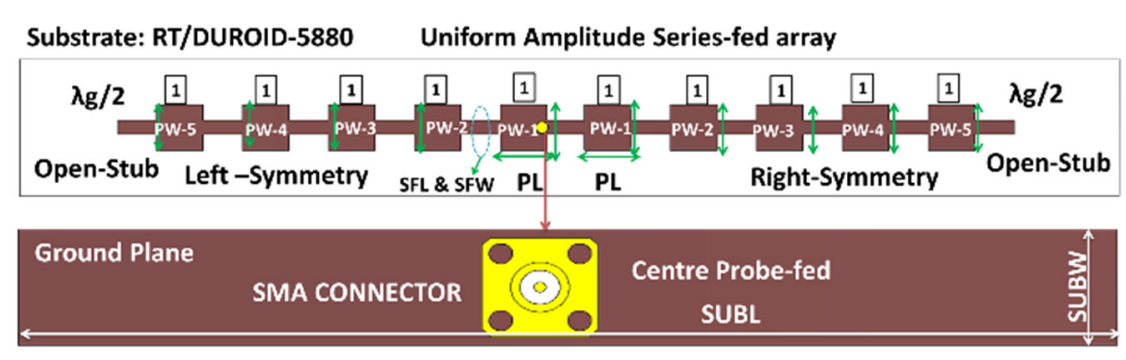

(a)

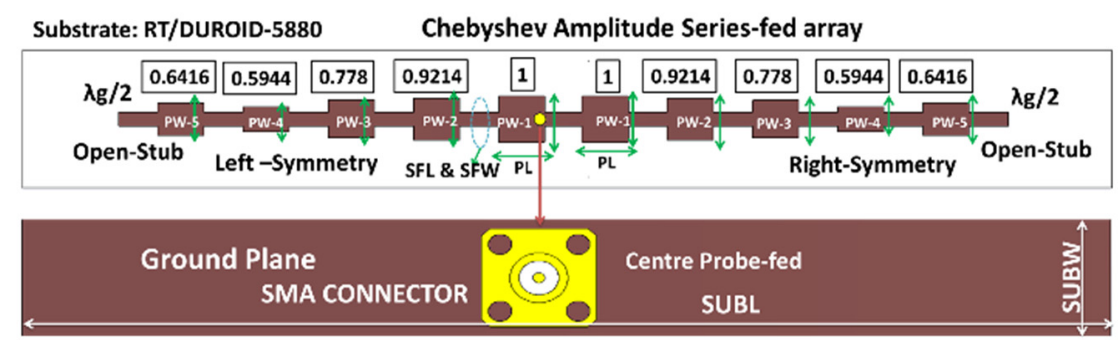

(b)

Fig. 1. Geometry of the configuration with optimized dimensions: (a) 10-element series-fed uniform linear array and (b) 10-element series-fed Chebyshev linear array. 
$=2.2$, and the loss tangent $\tan \delta=0.0009$ is chosen as the substrate material. After the fabrication of the antenna, we perform gold plating over the patch and the ground copper layer of $1-\mu$ thickness for the ULA and silver plating for the CLA. Then, an antenna mounting plate with brass material of $0.8 \mathrm{~mm}$ thickness is mechanically fabricated and used to mount the antenna PCB using M2 (M-Metric Standard) stainless steel screws. The height of the antenna becomes $1.6 \mathrm{~mm}$ (electrical dimensions $=$ $0.158 \lambda_{g}$ ), which corresponds to the center frequency of $21 \mathrm{GHz}$. The optimized parameters are given in Table 1 .

In the SFCFOS array design, a uniform characteristic with a constant SLL of $-13 \mathrm{~dB}$ and a Chebyshev characteristic of -25 $\mathrm{dB}$ is chosen. To obtain a flat SLL performance, we use amplitude coefficients modified from an ordinary Chebyshev synthesis and introduce a half-wavelength open-ended stub after the last element for an effective utilization of transmitted power. The width of the center patch is $5 \mathrm{~mm}$. The patch width of the other elements is variable, with a ratio of $1,0.9214,0.778$, 0.5944 , and 0.6412 from the array center to the edges. The distance between two adjacent elements is $4.28 \mathrm{~mm}\left(0.7 \lambda_{0}\right.$ at 21 $\mathrm{GHz}$ ). The whole size of the proposed ULA and CLA antenna arrays are $120 \mathrm{~mm}(L) \times 15 \mathrm{~mm}(W) \times 1.587 \mathrm{~mm}(H)$ and $100 \mathrm{~mm}(L) \times 15 \mathrm{~mm}(W) \times 0.787 \mathrm{~mm}(H)$, respectively. The array factor of the series array for an even number of elements can be written as (1):

$$
\begin{gathered}
(A F)_{2 M}=\sum_{n=1}^{5} a_{n} \cos (2 n-1) \psi \\
\because \psi=k d \cos (\theta) \psi
\end{gathered}
$$

Table 1. Optimized parameters of a 10-element linear array

\begin{tabular}{lccc}
\hline \multicolumn{1}{c}{ Parameter } & Value $(\mathrm{mm})$ & $\lambda_{0}$ & $\lambda_{g}$ \\
\hline 10-element ULA & & & \\
PL & 5 & 0.352 & 0.496 \\
PW-1 to PW-5 & 5 & 0.352 & 0.496 \\
SFL & 4.28 & 0.301 & 0.424 \\
SFW & 1.5 & 0.105 & 0.148 \\
10-element CLA & & & \\
PL & 5 & 0.352 & 0.496 \\
PW-1 & 5 & 0.352 & 0.496 \\
PW-2 & 4.6 & 0.323 & 0.456 \\
PW-3 & 4.15 & 0.292 & 0.411 \\
PW-4 & 2.75 & 0.193 & 0.272 \\
PW-5 & 3.5 & 0.246 & 0.347 \\
SFL & 4.28 & 0.301 & 0.424 \\
SFW & 1.5 & 0.105 & 0.148 \\
\hline
\end{tabular}

$\overline{\lambda_{0}}=$ free space wavelength with respect to the velocity of propagation in the air center frequency $(21 \mathrm{GHz})(0.0142 \mathrm{~m}), \lambda_{g}=$ guided wavelength with respect to the velocity of propagation in the substrate material (RT/Duroid-5880) (0.01008 m), PL = length of the patch, $\mathrm{PW}=$ width of the patch, SFL = length of the series-fed line, SFW = width of the series-fed line.

$$
\begin{gathered}
\psi=\frac{2 \pi}{\lambda} 0.7 \lambda \cos (\theta) \\
\text { Let } \mathrm{M}=5 \\
(A F)_{10}=a_{1} \cos (\psi)+a_{2} \cos (3 \psi)+a_{3} \cos (5 \psi)+a_{4} \cos (7 \psi)+a_{5} \cos (9 \psi) .
\end{gathered}
$$

\section{FABRICATED AND MEASURED RESULTS}

The proposed ULA and CLA antenna arrays are fabricated and measured. Fig. 2 presents a photograph of the fabricated antenna arrays showing the ULA and CLA antenna arrays assembled with a brass plate and stainless steel screws. The measured return loss of the ULA and CLA antenna arrays is performed with the Agilent N9918A FieldFox microwave analyzer. The radiation patterns and gains of the antenna array are measured using a far-field measurement technique in a microwave anechoic chamber with the Agilent PNA Series Network Analyzer N5230C (10 MHz-40 GHz).

\section{Impedance Bandwidth}

The uniform and Chebyshev 10-element series-fed linear arrays are fabricated and measured to validate the design. Fig. 2 shows the prototype array antenna for K-band applications. The measurement setup for both $S$-parameters and radiation patterns are shown in Fig. 3. The simulated structure using the CST Microwave Studio Simulator shows the electric field distribution illustrated in Fig. 4. The measured return loss $\left|S_{11}\right|$ of the proposed K-band 10-element series-fed uniform and Che-

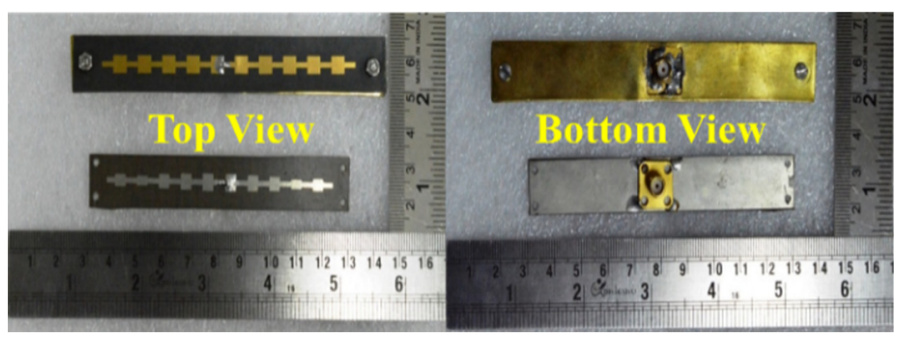

(a)

(b)

Fig. 2. Photograph of the fabricated prototypes: (a) Top view of the ULA and CLA and (b) Bottom view of the ULA and CLA.

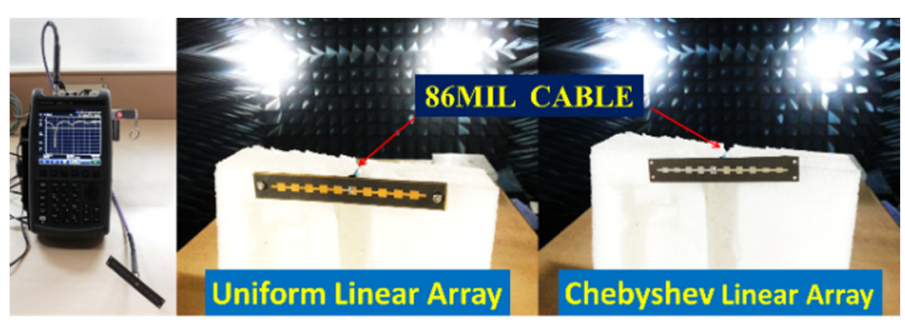

(a)

(b)

Fig. 3. $S$-parameters and radiation pattern measurement setup: (a) ULA and (b) CLA. 

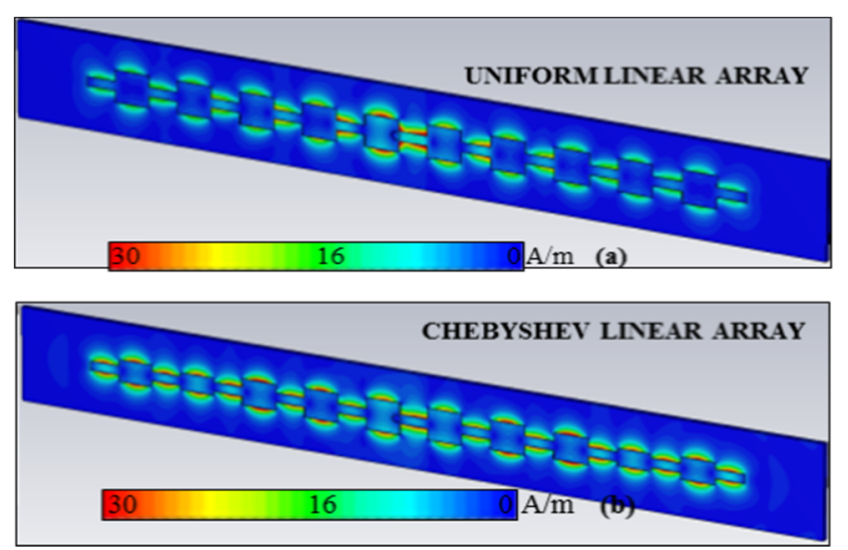

Fig. 4. (a) Uniform amplitude distribution-surface current distribution at $21 \mathrm{GHz}$ and (b) Chebyshev amplitude distributionsurface current distribution at $21 \mathrm{GHz}$.

byshev linear arrays is presented in Fig. 5. The measured -10 $\mathrm{dB}$ impedance bandwidth varies at $20.912-21.192 \mathrm{GHz}(1.33 \%)$ for the uniform array and at 20.89-21.196 GHZ (1.45\%) for the Chebyshev array with a resonant frequency of $21 \mathrm{GHz}$ for each design.

\section{Radiation Characteristics}

Figs. 6 and 7 show the radiation performance of the simulated and measured results of ULA and CLA, respectively, for the $\mathrm{K}$-band. The radiation is a linear vertical polarization with a

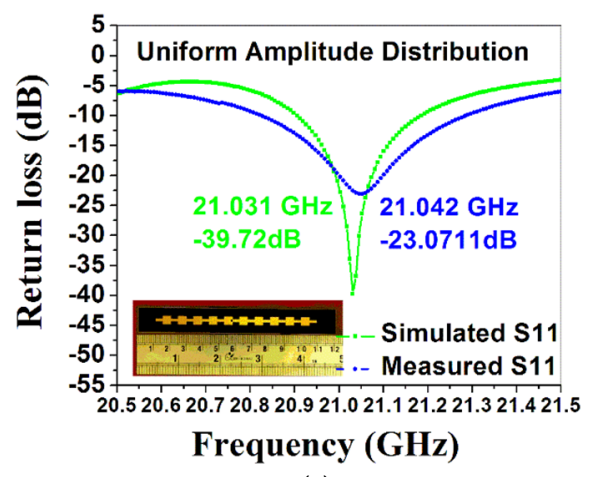

(a)

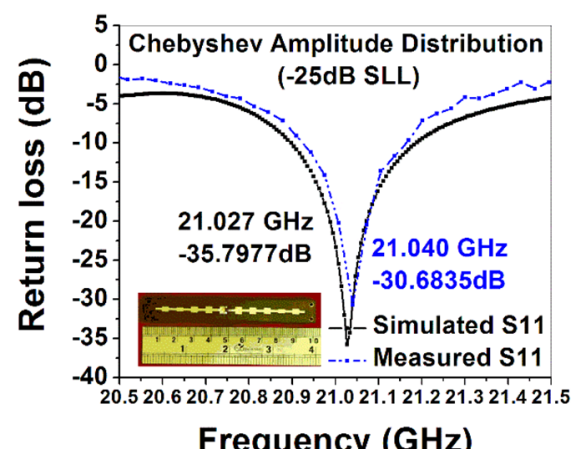

(b)

Fig. 5. Simulated and measured reflection coefficients: (a) ULA and (b) CLA.

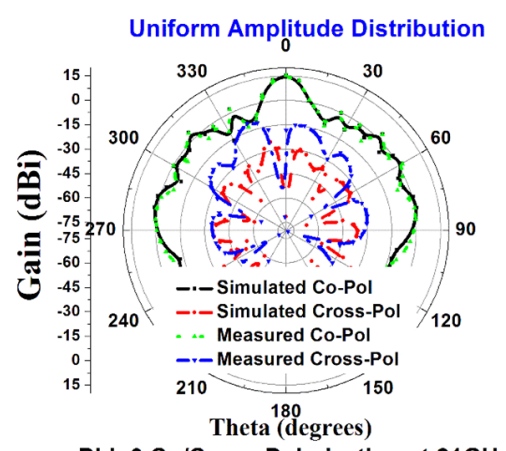

(a)

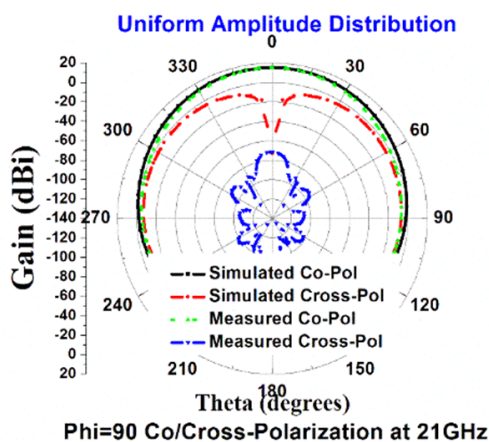

(b)

Fig. 6. Simulated and measured radiation patterns for the ULA at $21 \mathrm{GHz}$ : (a) $\phi=0^{\circ}$ E-plane (co-pol and cross-pol) and (b) $\phi=90^{\circ} \mathrm{H}$-plane (co-pol and cross-pol).

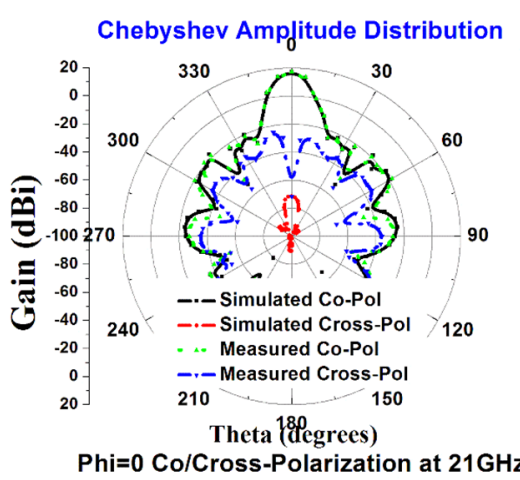

(a)

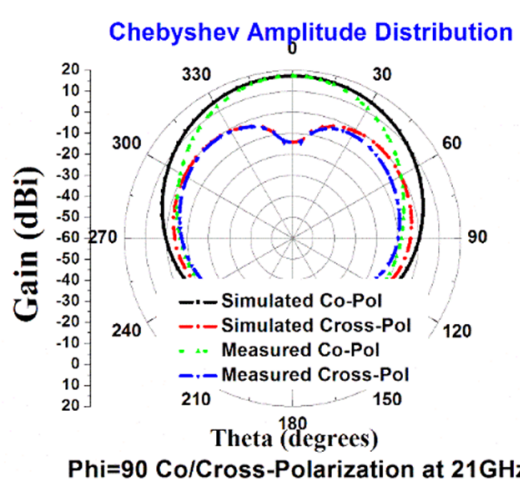

(b)

Fig. 7. Simulated and measured radiation patterns for the CLA at $21 \mathrm{GHz}$ : (a) $\phi=0^{\circ}$ E-plane (co-pol and cross-pol) and (b) $\phi=90^{\circ} \mathrm{H}$-plane (co-pol and cross-pol). 
high front-to-back ratio and a highly symmetric profile in both the $x-z$ and $y-z$ planes.

For the ULA design, the measured antenna gain is $15.3 \mathrm{dBi}$ with HPBWs of $10.4^{\circ}$ and $64.4^{\circ}$ for the $\phi=0^{\circ}$ (E-plane) and $\phi$ $=90^{\circ}$ (H-plane), respectively. The maximum SLLs are -10.4 $\mathrm{dB}$ and $-26.4 \mathrm{~dB}$ for the $\phi=0^{\circ}$ (E-plane) and $\phi=90^{\circ}(\mathrm{H}-$ plane) in the case of ULA. For the CLA design, the measured antenna gain is $17.4 \mathrm{dBi}$ with HPBWs of $9.1^{\circ}$ and $64.9^{\circ}$ for the E-plane and $\mathrm{H}$-plane, respectively. The maximum SLLs are $-26.3 \mathrm{~dB}$ and $-26.3 \mathrm{~dB}$ for the E-plane and $\mathrm{H}$-plane, respectively, in the case of CLA. From the measured results, the SLL reduction of greater than $-12 \mathrm{~dB}$ and gain enhancement of greater than $2 \mathrm{dBi}$ can be obtained simultaneously. The simulated radiation efficiency and the measured and simulated realized gains are shown in Fig. 8 for both the ULA and CLA arrays. Fig. 9 shows the 3D far-field gain. The results agree well with the simulated and measured antenna parameters. The radia-

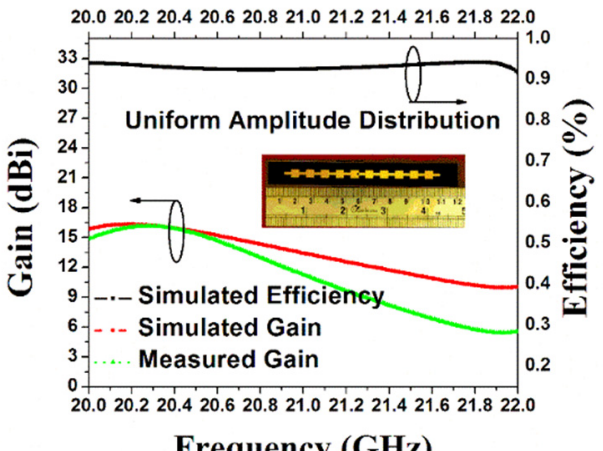

Frequency $(\mathbf{G H z})$

(a)

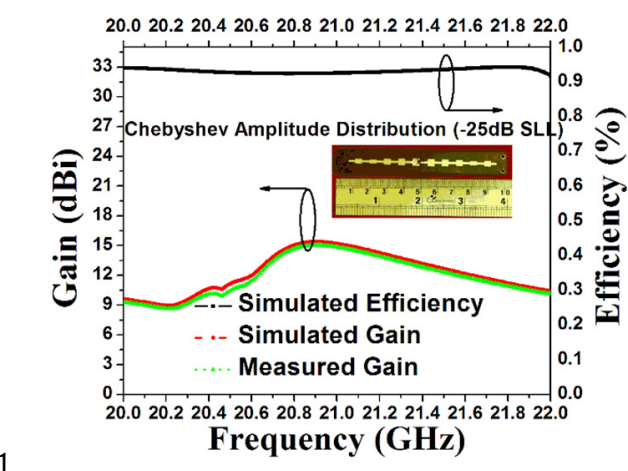

(b)

Fig. 8. Simulated radiation efficiency and measured gain: (a) ULA and (b) CLA.
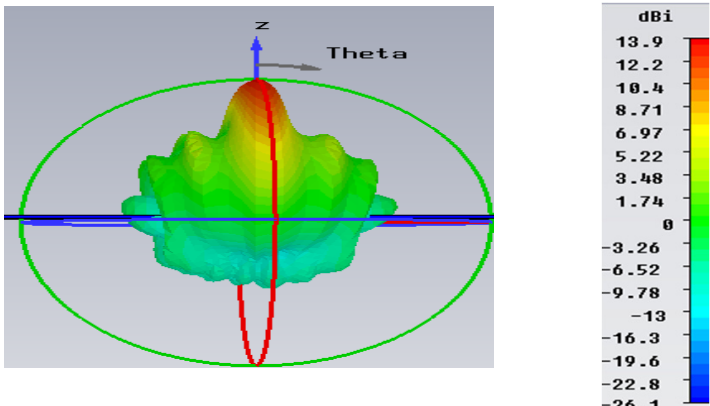

(a)
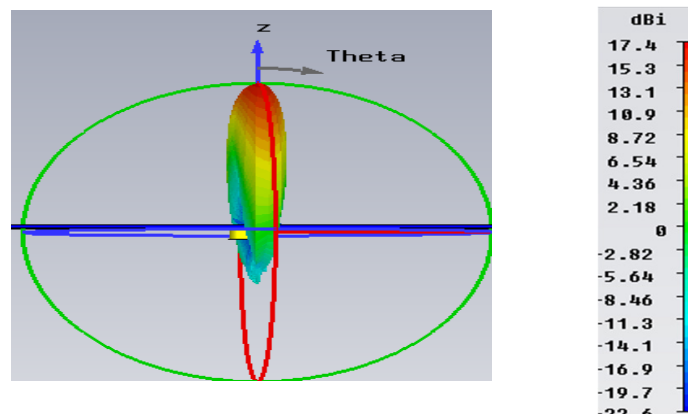

(b)

Fig. 9. Simulated 3D far-field gain: (a) $\phi=0^{\circ}$ (E-plane) ULA at $21 \mathrm{GHz}$ and (b) $\phi=0^{\circ}$ (E-plane) CLA at $21 \mathrm{GHz}$.

tion discrepancies between the simulation and the measurement are attributed to the fabrication errors. UAD and CAD has been compared with literature in Table 2.

The results of this work are compared with those in the literature in Table 3. The proposed array has a gain of $17.4 \mathrm{dBi}$ with the same number of elements, and it is higher than that in [13] with only $14.5 \mathrm{dBi}$ and in [15] with approximately 15.7 $\mathrm{dBi}$. In this work, the SLL is $1 \mathrm{dBi}$ higher than that in [13] and $3 \mathrm{~dB}$ higher than that in [15]. Compared with that in [16], the antenna has better gains and SLL results.

\section{CONCLUSION}

A novel SFCFOS antenna design for K-band radar applications is presented in this letter. The antenna structure shows a high gain performance and a low sidelobe level with a conformal size. The measured results are in good agreement with the simulated ones with gains of $15.3 \mathrm{dBi}$ and $17.4 \mathrm{dBi}$, respectively.

Table 2. Comparison with the uniform amplitude distribution

\begin{tabular}{lccccccc}
\hline \multicolumn{1}{c}{ Ref. } & Year & $\begin{array}{c}\text { No. of ele- } \\
\text { ments }\end{array}$ & SLL $(\mathrm{dB})$ & HPBW $\left(^{\circ}\right)$ & $\begin{array}{c}\text { Resonant frequency } \\
(\mathrm{GHz})\end{array}$ & Gain $(\mathrm{dBi})$ & Beam scan range $\left(^{\circ}\right)$ \\
\hline$[19]$ & 2004 & $1 \times 4$ & -9 & 25 & 2 & 8.7 & 20 \\
{$[20]$} & 2007 & $1 \times 5$ & -10 & N/A & 5.8 & 22.3 & N/A \\
{$[21]$} & 2010 & $1 \times 8$ & -10 & N/A & 2 & 15.3 & 25 \\
This work & - & $1 \times 10$ & -25 & 10.4 & 21 & \\
\hline
\end{tabular}


Table 3. Comparison with the Chebyshev amplitude distribution

\begin{tabular}{|c|c|c|c|c|c|c|c|}
\hline Ref. & Year & $\begin{array}{l}\text { No. of ele- } \\
\text { ments }\end{array}$ & SLL (dB) & $\operatorname{HPBW}\left({ }^{\circ}\right)$ & $\begin{array}{c}\text { Resonant frequency } \\
(\mathrm{GHz})\end{array}$ & Gain (dBi) & Beam scan range $\left(^{\circ}\right)$ \\
\hline [14] & 2013 & $1 \times 22$ & -30 & NA & 9.2 & 19 & $\mathrm{NA}$ \\
\hline$[15]$ & 2016 & $1 \times 10$ & -27.5 & NA & 60 & 15.7 & NA \\
\hline$[16]$ & 2017 & $1 \times 8$ & -23.1 & NA & 7.54 & 15.7 & NA \\
\hline [13] & 2017 & $1 \times 10$ & -25.3 & 8.3 & 9 & 14.5 & NA \\
\hline This work & - & $1 \times 10$ & -26.3 & 9.1 & 21 & 17.4 & 25 \\
\hline
\end{tabular}

The gain enhancement greater than $1.5 \mathrm{dBi}$ can be obtained with an SLL of $-25 \mathrm{~dB}$ using the CLA with 10 elements in the operating frequency band of 20.9-21.19 GHz. The HPBWs for the CLA/ULA at both E-plane and H-plane are $9.1^{\circ} / 10.4^{\circ}$ and $64.4^{\circ} / 64.9^{\circ}$, respectively. With these advantages, the proposed antenna array is a good candidate for use in radar systems.

\section{REFERENCES}

[1] W. Menzel, "A $40 \mathrm{GHz}$ microstrip array antenna," in Proceedings of IEEE MTT-S International Microwave Symposium Digest, Washington, DC, 1980, pp. 225-226.

[2] T. Metzler, "Microstrip series arrays," IEEE Transactions on Antennas and Propagation, vol. 29, no. 1, pp. 174-178, 1981.

[3] Y. B. Jung, I. Yeom, and C. W. Jung, "Centre-fed series array antenna for K-/Ka-band electromagnetic sensors," IET Microwaves, Antennas \& Propagation, vol. 6, no. 5, pp. 588-593, 2012.

[4] M. Hajian, J. Zijderveld, A. A. Lestari, and L. P. Ligthart, "Analysis, design and measurement of a series-fed microstrip array antenna for X-band INDRA: the Indonesian maritime radar," in Proceedings of the 3rd European Conference on Antennas and Propagation, Berlin, Germany, 2009, pp. 1154-1157.

[5] J. Hautcoeur, E. M. Cruz, J. Bartholomew, J. Sarrazin, Y. Mahe, and S. Toutain, "Low-cost printed antenna array built with hybrid feed for urban microwave links," IET Microwaves, Antennas \& Propagation, vol. 4, no. 9, pp. 13201326, 2010.

[6] H. Iizuka, K. Sakakibara, T. Watanabe, K. Sato, and K. Nishikawa, "Millimeter-wave microstrip array antenna with high efficiency for automotive radar systems," $R \& D$ Review of Toyota CRDL, vol. 37, no. 2, pp. 7-12, 2002.

[7] M. Barba, "A high-isolation, wideband and dual-linear polarization patch antenna," IEEE Transactions on Antennas and Propagation, vol. 56, no. 5, pp. 1472-1476, 2008.

[8] B. Lee, S. Kwon, and J. Choi, "Polarisation diversity microstrip base station antenna at $2 \mathrm{GHz}$ using t-shaped aperture-coupled feeds," IEE Proceedings-Microwaves, Antennas and Propagation, vol. 148, no. 5, pp. 334-338, 2011.

[9] B. Li, Y. Z. Yin, W. Hu, Y. Ding, and Y. Zhao, "Wide- band dual-polarized patch antenna with low cross polarization and high isolation," IEEE Antennas and Wireless Propagation Letters, vol. 11, pp. 427-430, 2012.

[10] J. Xiao, G. Dong, and M. Zhu, "A novel aperture coupled microstrip antenna array with low cross-polarization, low sidelobe and backlobe," in Proceedings of the 4th International Conference on Microwave and Millimeter Wave Technology (ICMMT), Nanjing, China, 2004, pp. 223-226.

[11] Y. P. Saputra, F. Oktafiani, Y. Wahyu, and A. Munir, "Side lobe suppression for X-band array antenna using Dolph-Chebyshev power distribution," in Proceedings of the 22nd Asia-Pacific Conference on Communications (APCC), Yogyakarta, Indonesia, 2016, pp. 86-89.

[12] C. Niu, J. She, and Z. Feng, "Design and simulation of linear series-fed low-sidelobe microstrip antenna array," in Proceedings of the Asia-Pacific Microwave Conference (APMC), Bangkok, Thailand, 2007, pp. 1-4.

[13] J. Yin, Q. Wu, C. Yu, H. Wang, and W. Hong, "Low sidelobe-level series-fed microstrip antenna array of unequal interelement spacing," IEEE Antennas and Wireless Propagation Letters, vol. 16, pp. 1695-1698, 2017.

[14] M. R. Nikkhah, J. Rashed-Mohassel, and A. A. Kishk, "A low sidelobe and wideband series-fed dielectric resonator antenna array," in Proceedings of the 21st Iranian Conference on Electrical Engineering (ICEE), Mashhad, Iran, 2013, pp. $1-3$.

[15] W. Shen, J. Lin, and K. Yang, "Design of a V-band low sidelobe and wideband linear DRA array," in Proceedings of the Progress in Electromagnetic Research Symposium (PIERS), Shanghai, China, 2016, pp. 477-480.

[16] J. Lin, W. Shen, and K. Yang, "A low-sidelobe and wideband series-fed linear dielectric resonator antenna array," IEEE Antennas and Wireless Propagation Letters, vol. 16, pp. 513-516, 2017.

[17] R. Bayderkhani and H. R. Hassani, "Wideband and low sidelobe linear series fed Yagi-like antenna array," Progress In Electromagnetics Research, vol. 17, pp. 153-167, 2009.

[18] R. Bayderkhani and H. R. Hassani, "Wideband and low sidelobe slot antenna fed by series-fed printed array," IEEE Transactions on Antennas and Propagation, vol. 58, no. 12, pp. 3898-3904, 2010. 
[19] A. Tombak and A. Mortazawi, "A novel low-cost beamsteering technique based on the extended-resonance power-dividing method," IEEE Transactions on Microwave Theory and Techniques, vol. 52, no. 2, pp. 664-670, 2004.

[20] E. Ojefors, S. Cheng, K. From, I. Skarin, P. Hallbjorner, and A. Rydberg, "Electrically steerable single-layer microstrip traveling wave antenna with varactor diode based

\section{Venkata Kishore Kothapudi (S, 14 M, 2018)}

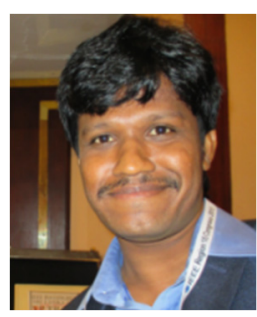

was born in Tenali Town, Guntur district, Andhra Pradesh, India, in 1987. He received a degree in Electronics and Communication Engineering from TPIST, JNTU, Hyderabad, India, in 2008 and M.Tech. degree in Communication and Radar Systems from the Koneru Lakshmaiah Education Foundation (KLEF), India, in 2012. He is currently pursuing a Ph.D. degree with the Microwave Division, department of Communication Engineering, School of Electronics Engineering (SENSE), Vellore Institute of Technology (VIT), Vellore, Tamil Nadu India. He has more than 7+years of Research and Industry experience in RF and Microwave engineering in ECIL as a GEA, in NARL-ISRO as a project student, Astra Microwave Products as an Engineer, Research Associate and Teaching Cum and Research Associate in Microwave Division, department of Communication Engineering, School of Electronics Engineering (SENSE), Vellore Institute of Technology (VIT). He has rich experience in radar systems design, which includes transmit/receive modules (HF, VHF, L, $\mathrm{S}$, and C-Band), RF and microwave feeder network and beam forming, $\mathrm{RF}$ and microwave active and passive components, RF power amplifiers, and antenna systems, which include Yagi-Uda and microstrip patch antenna as a phased array with different configurations using analysis and synthesis techniques. He has published more than 15 research papers in international journals and national and IEEE international conferences. He has been the author and co-author of many IEEE Proceedings papers. He has published research papers in IEEE Access, with a 3.557 impact factor; the Progress in Electromagnetic Research (PIER) international journal, Journal of Electromagnetic Engineering and Science (JEES), and IEEE international conferences. He is reviewer for several reputed journals (IEEE Access, JEES, ACES, Advanced Electromagnetics JESTR.) He travelled to Sri Lanka and Singapore for the IEEE SYWC 2015 meeting and the IEEE APSAR 2015 conference, respectively, to present his research work and as a part of his research. His research interests include Shared Aperture Antenna Technology (Single-Layer and Multi-Layer-P/L/S/C/X/Ku/K/Kabands) for Radar Engineering, Airborne and Space borne Synthetic Aperture Radar, and Radar Wind Profilers. He is a member of Institute of Electrical and Electronics Engineering (IEEE), American Institute of Aeronautics and Astronautics (AIAA), and Applied Computational Electromagnetics Society (ACES). He is associated with IEEE societies (AP-s., MTT-s., AES-s., GRS-s., IP-s., ComSoc \& EMC-s.). phase shifters," IEEE Transactions on Antennas and Propagation, vol. 55, no. 9, pp. 2451-2460, 2007.

[21] D. Ehyaie and A. Mortazawi, "A new approach to design low cost, low complexity phased arrays," in Proceedings of IEEE MTT-S International Microwave Symposium Digest, Anaheim, CA, 2010, pp. 1270-1273.

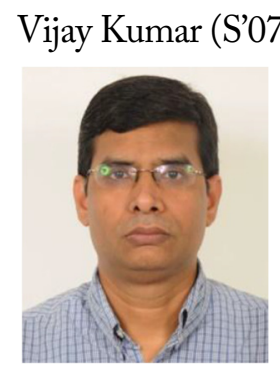

\section{M'11-SM'18}

received his M.Sc. degree in electronics from the Magadh University, India, in 2003. He obtained his M.Tech. degree in microwave remote sensing systems from BIT Mesra, Ranchi, in 2005 and his $\mathrm{Ph} . \mathrm{D}$. in microwave system engineering from IIT Bombay, Mumbai, in 2011. He worked as research associate in IIT Bombay and focused on Synthetic Aperture Radar interferometry and polarimetry for snow and ice studies in the Himalayas. He worked as a scientist investigator sponsored by the DST Government of India at CSRE, IIT Bombay in 2009-2013. He was a visiting researcher at Earth Observation Group, Northern Research Institute in 2009-2010. Kumar is an associate professor at the School of Electronics Engineering, VIT University and Vellore, TN, India beginning from 2013 until the present. He is associated with the photonics and microwave group at VIT. His research interests are microwave imaging and radar and SAR imaging system development and applications in Earth observation and reconnaissance from spaceborne, airborne, and UAV platforms. He is the author and contributing author of more than $20 \mathrm{SCI}$ peer-reviewed papers and 30 conference proceedings on radiating system designs for radar applications, miniaturized antenna design using metamaterials, and MIMO antenna systems for UWB applications with reconfigurable notch band characteristics. He worked on active devices such as LNA and PAs for the UHF-range wind profiler radars. He completed two Ph.D. guidelines on MTM loaded antenna design and shared aperture beamforming array for radar applications. He guided five M.Tech theses on antenna design area. He completed three funded projects on antennas for radar applications, SAR processing, and multi-aperture SAR interferometry techniques. His current research interests are microwave active and passive device designs, $\mathrm{THz}$ antennas, and trans-receiver system for automotive radar applications. He is a life member of Indian Society of Remote Sensing (ISRS) and International Society for Optics and Photonics (SPIE) and is actively associated with IEEE societies Antennas and Propagation Society (APS), Tera Hertz (THz), and Geoscience and Remote Sensing (GRSS). 